\title{
Prospects of engine building transformation to the hydrogen-containing fuel
}

\author{
Viktor Barelko ${ }^{1}$, Oleg Brizitsky ${ }^{2}$, Maxim Kuznetsov ${ }^{3 *}$, Ivan Parkin ${ }^{4}$, and Alexey Safonov ${ }^{3}$ \\ ${ }^{1}$ Institute of Problems of Chemical Physics, Russian Academy of Sciences \\ ${ }^{2}$ Russian Federal Nuclear Center-All-Russian Research Institute of Experimental Physics \\ ${ }^{3}$ All-Russian Research Institute on Problems of Civil Defense and Emergencies (Federal center of \\ science and Hi-Tech) of Emergency Control Ministry of Russia (EMERCOM) \\ ${ }^{4}$ Department of Chemistry, Materials Chemistry Research Centre, University College London
}

\begin{abstract}
Promising developments in the field of engine building, associated with increasing of natural gas usage as a motor fuel for internal combustion engines (ICE), are presented. Technology of hydrogencontaining fuel composition forming created. Advantages of motor transport based on ICE with GHA: lower amount of toxic (reduction of CO release) of about 7 times; retention of existing infrastructure of fuel supply with decrease of fuel consumption of $12-17 \%$; safety; reasonable combination of advantages of hydrocarbon and hydrogen power engineer. The perspectives of modified engines for the various interested organizations and ministries operating gasoline and diesel vehicles are discussed.
\end{abstract}

\section{Introduction}

Currently, in Russian and world practice, the common strategy for the development of fuel and energy complex in the field of civil and special-purpose engines is the natural gas usage as a motor fuel. In Russia at Federal and regional levels the question of transfer the natural gas vehicles (especially heavy vehicles) and engine stand-alone power plants is studied intensively. A number of decisions of the Russian Government on expanding the natural gas usage as a motor fuel have been adopted. It is obvious that such transition can and will be economically beneficial only in the introduction of innovative energy-saving technologies. Piston engine not with spark ignition, but with a gas-diesel engine, running on natural gas with a fuse dose of diesel fuel, have been chosen as a basic engine for the study of the proposed technological approaches. This type of engine makes it possible to realize the advantages of innovative technology and get a large-scale effect, because the diesel engine is the most massive engine in the country. The main problem with this type of engine are that it is dominant in transport and efficiently operate mainly at medium and nominal loads, i.e. in the regime of country drive with a speed above $60 \mathrm{~km} / \mathrm{h}$. In the urban car driving cycle engine has the efficiency to a maximum of $10 \%$, i.e. the remaining $90 \%$ leave on heating of environment and poisoning all the inhabitants of the towns with nitrogen oxides, carbon monoxide, etc. It is necessary once again to look attentively at the old and tested time of

* Corresponding author: maxim1968@mail.ru 
internal combustion engines. All of their improvements over the past decades have been focused mainly on dosing and exhaust systems, and small attention has been paid to the combined cycle of the engine. Meanwhile, the engine has become so dynamic that all processes - dosing, spraying, ignition, fuel combustion - can occur in hundredths of a second, and traditional gasoline can no longer keep up with these processes. But hydrogen, which is having almost eight times the speed of combustion than gasoline, is a good but expensive substitute for gasoline. However, it turned out that there is no need to completely replace the traditional fuel, it is enough to introduce 1-6\% of hydrogen into it (by mass) and its combustion processes may be significantly improved. This may be explained by the initiating effect of hydrogen, which forms the combustion centers. At one time, academician Y.B. Zeldovich described these phenomena in great detail in his theory of combustion. This increases the efficiency of engine, and improves its environmental performance. Here there are several choices. Refuel, for example, at special hydrogen gas stations, that will need to be built up. At the same time, there are also a few options: to fill up hydrogen in the special tanks of the car and, depending from the nature of the trip, to dose its consumption in small portions, or to add it, when refueling entirely into the main fuel [1-5]. The first way is an attractive and effective, it can be used for any kind of main fuel, but it also requires the car refinement, because the car becomes a two-fuel. The second way is only possible when using gaseous as a main fuel, for example, natural gas. The engine does not requiring any improvements, it is still a single fuel, but the efficiency of such system is not the highest, because hydrogen in the mixture is prepared in advance, and it is impossible to use it more efficiently, as in the first version [6-8].

\section{Experimental}

The device we are developing is a synthesis gas generator, which is free from most of disadvantages of previous variants. Firstly, there are no needs of building up hydrogen fueling stations, availability of additional electric power and distilled water on board of the vehicle. Secondly, the cost of such generator is several times lower, than the cost of an electrolyzer. There are no precious metals in its composition, which removes the restriction on mass production. The most optimal way was the natural gas usage as a main fuel, which is a good motor fuel itself. The hydrogen yield is high and the generator is relatively simple. We have developed generators of synthesis gas passed the demonstration test bench. Almost everywhere, not only sharp decrease in harmful emissions, but also significant (up to $24 \%$ ) increase of efficiency in an urban driving was received.

The following goals were set and achieved:

- reduction in the size of the fuse dose of diesel fuel from 20 to $5-8 \%$, which will lead to a reduction in the diesel component in equivalent fuel (natural gas plus diesel fuel) from $50 \%$ to $10-20 \%$, i.e. a significant reduction in the cost of generated electricity (up to $40 \%$ );

- significant improvement in the environmental performance of the power plant: reduction of soot emissions, $\mathrm{CO}, \mathrm{CH}$ and $\mathrm{NOx}$ content in the engine exhaust.

At this stage of development, as the main objects have been selected engines, which are used in fixed systems of power from a wide range of engines, including Arctic regions of Russia. This factor is extremely relevant due to the multiple expansion of state activity in all the areas. This choice was made on the basis of the following considerations:

1) rather limited (in comparison with the engines of vehicles), but very demanded market of engines of such appointment;

2) ability to move as quickly as possible to the practical development of the catalytic converters of hydrogen components in the fuel path of these engines, associated with the ease of the catalytic link operation, when the system is in stationary mode; 
3) acute demand in the improvement of such installations on environmental parameters and energy saving indicators;

4) very wide range of engines for the power plants on capacities that will allow to develop the process of fuel tract modernization, moving consistently from the low-power and smallsized engines to the powerful motor systems;

5) saved-up experience of work with stationary engines for autonomous power engineering will create conditions for its subsequent effective usage at transition to engines of vehicles, first of all, to the heavy motor transport and engines of a special purpose.

Onboard synthesis gas generator (SGG) is a device that converts a part of a primary fuel (natural gas in this work) to hydrogen-rich gas (synthesis gas) which is fed to the engine together with the main fuel (natural gas or gasoline). Consider the simplest version of SGG on the basis of air reforming of natural gas. Variants with other fuels will differ only by feed and dosing systems. SGG for onboard vehicle (for example, minivan) application contains the following units:

- system for feeding and dosing of initial components (fuel, air), which includes air compressor, dozer, flowmeter, injector, "air-natural gas" mixer;

- reformer, which includes catalytic reactor for fuel conversion to syngas, quick starter of catalyst, systems for recuperation of reaction heat, temperature sensors, mixers;

- system for hydrogen-rich gas cooling (heat exchanger cooler);

- automatic controller of operation parameters.

SGG and internal combustion engines (ICE) configurations and control systems should be maximally integrated and operated according to control algorithm. Depending on the integrated operation mode, SGG performs the following functions: cold start mode; all modes of operation (except of closed-throttle deceleration mode): as SGG is warmed up, hydrogenrich gas is fed to ICE in the amount according to control algorithm; closed-throttle deceleration mode: supply of hydrogen-rich gas to ICE is terminated; stop mode: supply of initial components (fuel and air) to SGG is terminated, no hydrogen-rich gas is generated.

Special attention was focused on minimizing SGG start time. As a result, the catalyst was heated up from ambient temperature to $6000 \mathrm{C}$ in $11 \mathrm{~s}$ at flow rates of natural gas and air of $0.5 \mathrm{~m} 3 / \mathrm{h}$ and $5.2 \mathrm{~m} 3 / \mathrm{h}$, respectively (stoichiometry, $\lambda=1$ ). As the flow rates of natural gas and air was $2 \mathrm{~m} 3 / \mathrm{h}$ and $5.5 \mathrm{~m} 3 / \mathrm{h}$, SGG generated $9.6 \mathrm{~m} 3$ of hydrogen-rich gas. The temperature of hydrogen-rich gas at SGG outlet was 150-2000C; the flow rate of cooling agent did not exceed $100 \mathrm{~L} / \mathrm{h}$. According to test results, the SGG hydrogen-rich gas productivity ranged within $5-30 \mathrm{~m} 3 / \mathrm{h}$.

The developed system for onboard generation of hydrogen rich gas and its application as additive to primary fuel is principally different from hythane-based technical solutions reported in literature [9-12]. Since hythane fuel (methane 80\%, hydrogen 20\%) has fixed composition which can't be changed depending on ICE operation mode, it fails to use hydrogen advantages as fuel additive. The suggested solution is universal, flexible and allows variation of fuel-syngas proportion depending on ICE operation load. For example, for the purpose of fuel saving in idle mode, the engine is run on synthesis gas, that is not possible in case of hythane technology. Microprocessor-based control system provides the optimum operation of SGG according to special algorithm and holds the following functions:

- ICE control in cold and warm starting modes;

- provides the needed fuel-air proportion in all operation modes depending on temperatures of air and cooling agent, air flow rate, throttle angle, speed of throttle angle change, oxygen content in exhaust gases;

- provides the needed spark angle depending on gas hydrogen proportion in the fuel; control of SGG and ICE actuation mechanisms. 
Microprocessor operation algorithm is described in [13]. Figure 1 presents electronic control unit arranged for minivan "Sobol". More details on this development are also reported [13]. Technical solutions related to arrangement of SGG under vehicles cowling addressed the following requirements: compactness; minimization of hydraulic and heat losses; feasible visual and instrumental diagnostics. SGG was mounted in engine compartment of GAZ-2310 (Sobol) equipped with ZMZ-40522.10 ICE. SGG was mounted on left fender and cooled by engine cooling system. Hydrogen-rich gas from SGG was fed to ICE by flexible metal tubing through special air-gas mixer located upstream throttle valve. The SGG was mounted using a structure absorbing vibrations and impact stresses. Compressed gas equipment was placed in the bottom part of the car. Electronic control system was mounted on a metal shelve in the right part of engine compartment (see Fig. 2). Purchased component parts of SGG (air compressor, ignition coil, filter, flow controller, cutoff valves) were also mounted under the cowling using special bracketry. Specially developed feed control unit to provide ICE operation both on gasoline and natural gas was installed in the engine compartment. The mounted system allowed experiments on optimization of ICE operation with gasoline, natural gas, synthesis gas, gasoline or natural gas with syngas additives.

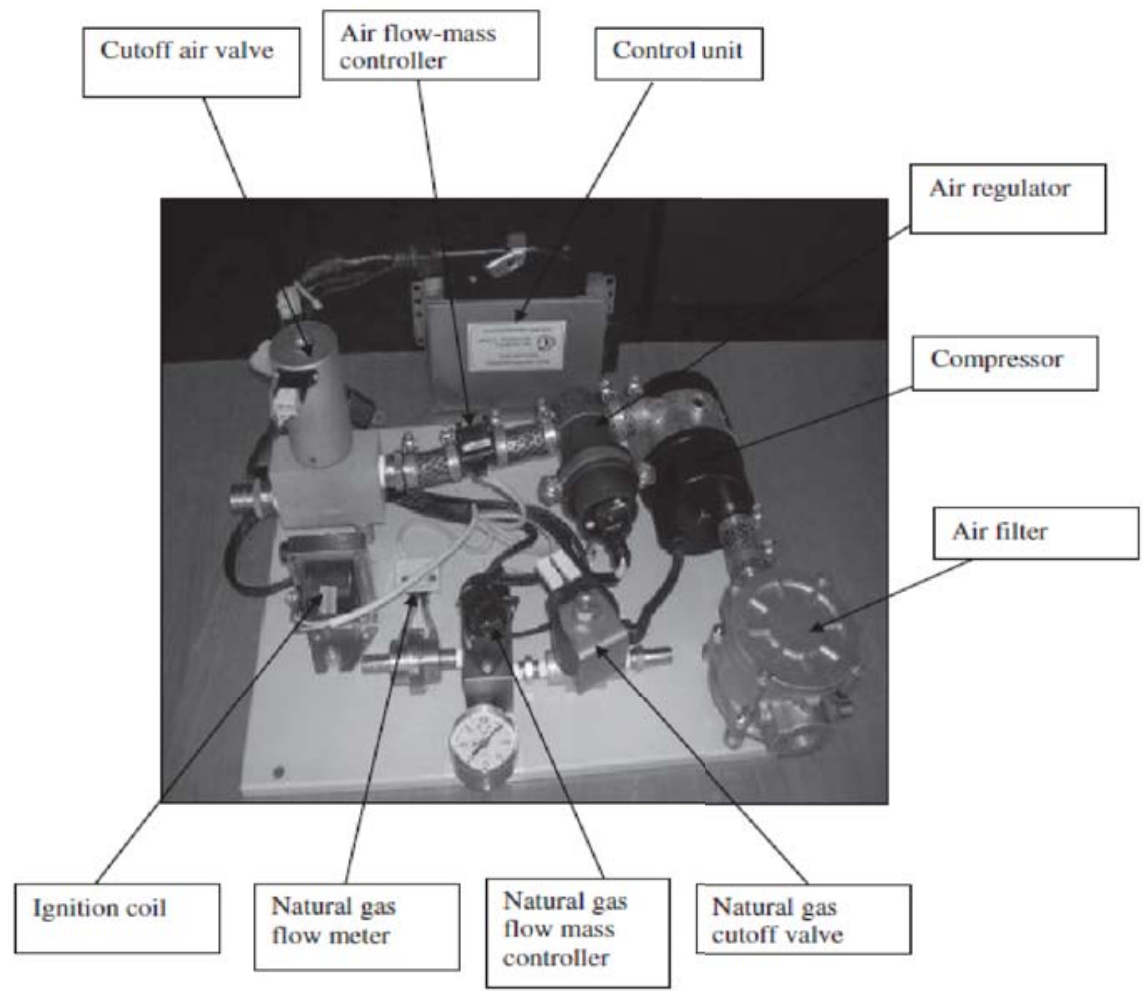

Fig.1. General view of electronic control unit. 


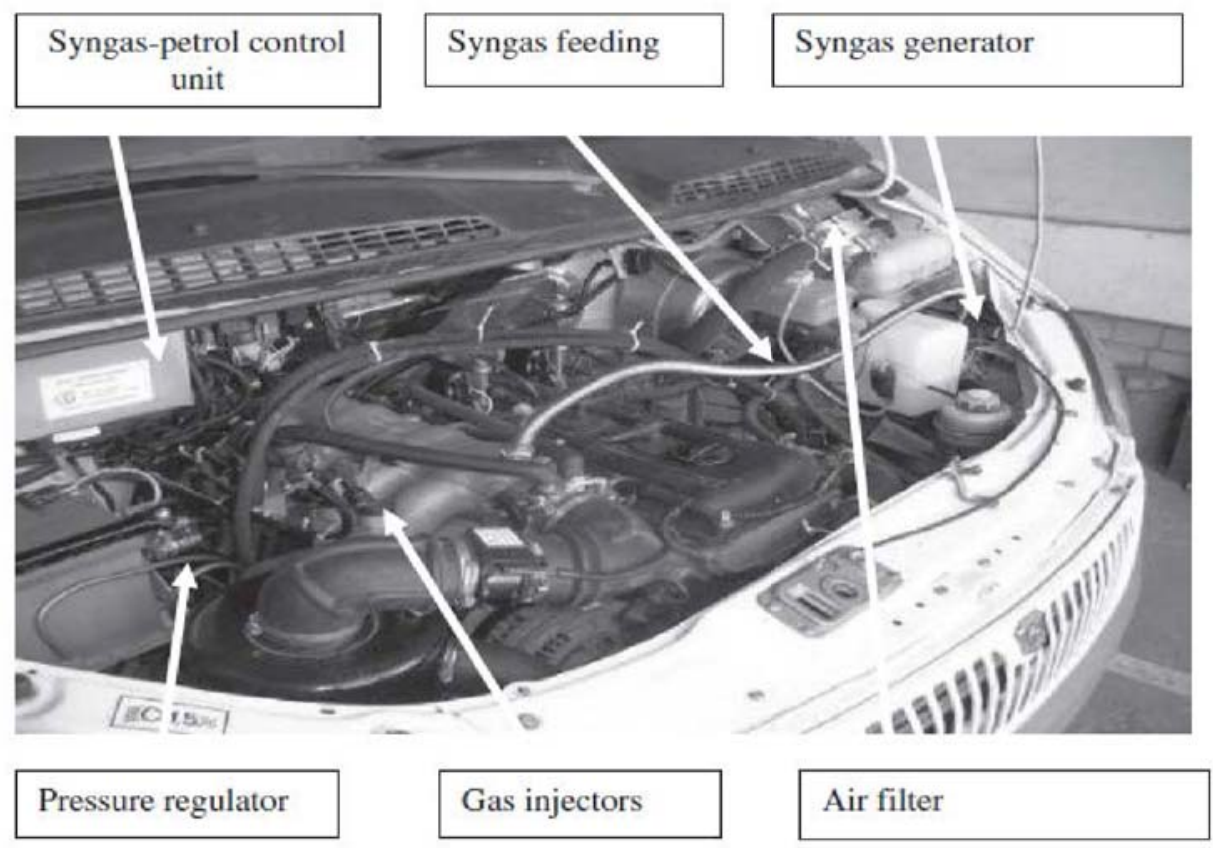

Fig.2. Arrangement of onboard synthesis gas generator and engine operating components in under engine cowling of minivan "Sobol".

Road tests were performed during "Blue Corridor” rally enroute Novgorod - St. Peterburg - Novgorod - Moscow, organized by GASPROM. Total kilometerage (including way from Rybinsk, Yaroslavl Region, to start position) of rally was $2235 \mathrm{~km}$. Minivan "Sobol" equipped with gas cylinders and SGG capable of producing 5-15 m3 syngas per h took part in the rally. During rally, full-scale trials were performed including in situ monitoring of emissions and fuel consumption. Particularly important, the minivan was capable to run on natural gas, methane-syngas mixture and on gasoline. This allowed measuring operation characteristics and estimating efficiency of syngas additive under similar conditions. Clearly, addition of synthesis gas to natural gas fuel facilitates the decrease of $\mathrm{CO}$ emission by 18 times, NOx - by 12 times, $\mathrm{CO} 2$ - 1.4 times, but increases $\mathrm{CH}$ emissions by 1.5 times. In general, these data confirm that synthesis gas additives help to decrease toxic emissions from vehicles. Acceleration time of the car fueled by natural gas with synthesis gas additive increases by $14-30 \%$, depending on the gear type. Costs per $100 \mathrm{~km}$ run on natural gas are 3.28 times lower then that on gasoline, and 3.84 times lower if natural gas is enriched with synthesis gas additive. Compared to vehicles fueling by natural gas, the use of natural gas with synthesis gas additive provides 1.17-times cost decrease and increases one-filling run by $62 \mathrm{~km}$. Note that optimization of ICE-SGG load characteristics will strengthen these effects considerably.

It should be also noted that our development of efficient, high-performance, small-sized synthesis-gas generators, based on catalytic conversion of natural gas, makes it possible to enter markets far beyond the automotive industry and the autonomous energy needs. The extensive demand for these devices is predicted for the various branches of civil and special purpose, in particular: in metallurgical and metal rolling industry (production of protective atmospheres); in the processes of chemical and thermal processing of metals and alloys (furnaces - generators of endo- and exo- gas in the technology of metal details cementation); in electronic industry at production of products on the basis of silicon and its oxides (formation of recovery environments) etc. 


\section{Conclusion}

The results of bench and road tests clearly prove that syngas additives both to gasoline and lean gas mixtures provide stable ICE operation, fuel saving and decrease of toxic emissions. With this technology, necessity to develop hydrogen generating, storing and refueling infrastructure disappears thus saving enormous money. The technology is free from hydrogen risks, because hydrogen is generated and used in situ. The technology provides stable ICE starting in winter due to combined effect of warmed up heat-carrier and hydrogen enriched fuel. Synthesis gas can be produced from diesel and biodiesel fuels, bioethanol, other biomass-derived fuels that widens its application opportunities as ICE fuel additive and $\mathrm{NO}_{\mathrm{x}}$ reducing agent $[14,15]$. The proposed technology represents initial step of wide scale works on the development of energy-efficient engines. The next step includes comprehensive tests with the use of various type engines and vehicles and modified technology using exhaust recycling in combination with air-steamcarbon dioxide reforming. These studies will allow improved fuel efficiency. Urban transport and municipal vehicle (buses, minivans, refusecollectors, street-cleaners, snow-removers, etc.) are the most promising application areas of the developed technology, because: urban traffic dictates start-stop driving style which makes switching to synthesis gas fueling most profitable; relatively low generator/vehicle price ratio; no need for most compact arrangement of synthesis gas generator onboard vehicle. Recently we were able to improve drastically a mass-dimension and dynamic characteristics of the synthesis gas generator for a passenger car. Reactor has a mass of $8 \mathrm{~kg}$ and a volume of 2.5 liters, and the launch is carried out in just 35 seconds, which is commensurate with the warm-up time of the neutralizer. The syngas generator installed on the bus will have almost the same cost as for a passenger car, which we estimate is about 20-30 thousand rubles. In the total cost of the bus the cost of the syngas generator will be a few percents, and for a passenger car it is about $10 \%$.

\section{References}

1. O.F. Brizitsky, V.Y. Terentyev, V.V. Barelko, V.A. Kirillov, V.A. Sobyanin, P.V. Snytnikov, V.A. Burtsev, L.A. Bykov, M.V. Kuznetsov. About the prospects of engine building industry conversion on hydrogen-rich fuel. Int Sci J AlternatEnergEcol 20:95$102(2014)$

2. V.V. Barelko, M.V. Kuznetsov, V.G. Dorokhov, I.P. Parkin. Fiberglass woven catalysts - alternative catalytic materials for various industries. Russ J PhysChemB 11:606-17 (2017)

3. Z.S. Andrianova, A.N. Ivanova, V.V. Barelko. Nonlinear phenomena in heterogeneous catalytic reactions with a branched-chain mechanism of formation of active centers. Russ J PhysChemB 3; 764-9 (2009)

4. B.S. Balzhinimaev, V.V. Barelko, S.P. Kildyashev, M.G. Makarenko, V.A. Chumachenko. Carrier and catalyst for heterogeneous reactions. RU Patent 2143948 (2000)

5. V.G. Dorokhov, V.V. Barelko, L.A. Bykov, R.A. Basimova, M.L. Pavlov, A.V. Askarova. Development and investigation of new-generation catalysts on a woven fiberglass support for styrene refining from the phenylacetylene impurity by selective hydrogenation. DoklChem; 438:148-150 (2011)

6. A.N. Ivanova, Z.S. Andrianova, V.V. Barelko. On the Theory of Nonlinear Phenomena in Catalytic Combustion Reactions. DoklPhysChem 386:257-61 (2008) 
7. V.V. Barelko, V.N. Zvyagin, V.Y. Onischenko, P.I. Khalzov. Catalyst for chemical processes, such as ammonia conversion, hydrocarbon oxidation, sulfur dioxide, exhaust gas purification. RU Patent 2069584 (1996)

8. V.G. Dorokhov, V.V. Barelko, M.V. Kuznetsov Hydrogenation of aromatic mononitrobenzene in the liquid phase deposited on a porous catalyst at partial pressures of hydrogen less than 0.1 MPa. Russ J ApplChem; 90:1621-31 (2017)

9. C.G. Bauer, T.W. Forest. Effect of hydrogen addition on the performance of methanefueled vehicles. Part 1: effect on S.I. engine performance. Int J HydrogenEnerg;26:5570 (2001)

10. V.K. Belnov, N.M. Voskresenskii, S.I. Serdyukov, I.I. Karpov, V.V. Barelko. Mathematical modeling of endothermic reactions in the catalyst unit with structured catalytic beds. ChemEngSci 58:4895-4901 (2003)

11. V.V. Barelko, Z.S. Andrianova, A.N. Ivanova. Domain instability in heterogeneous catalytic reactions controlled by branched-chain kinetics. DoklPhysChem 421:170-3. (2008)

12. V.V. Barelko, D.P. Kirjukhin, P.P. Kushch, G.A. Kichigina, V.G. Dorokhov, K.A. Bykov. Polymer-Glass Composite Material and Method for Production Thereof. RU Patent 2577053 (2016)

13. N.V. Burtsev, O.F. Brizitskii, V.A. Kirillov, V.N. Komarov, V.A. Sobyanin. Application of adaptive control methods for the development of microprocessor system for control of multi-fuel ICE with the use of synthesis gas. Vestnik NGU. SerInfTechnol 7:62-73. (2009)

14. V.A. Kirillov, E.I. Smirnov, Y.I. Amosov, A.S. Bobrin, V.D. Belyaev, V.A. Sobyanin. Reduction of nitrogen oxides in exhaust gases of diesel engines: perspectives of synthesis gas using. KinetCatal 50:22-30 (2009)

15. V.V. Barelko, A.P. Khrushch, A.F. Cherashev Non-Langmuir mechanisms of catalytic combustion reactions on platinum. ChemPhysReports 9:919-30 (2000) 